\title{
SSR Markers based Molecular Assessment of Stripe Rust Resistance Genes in F3 Population of Cross DBW17 x WH1105 of Wheat (Triticum aestivum L.)
}

\author{
Vijeta Gupta*, Mukesh Kumar, Vikram Singh and Lakshmi Chaudhary
}

Department of Genetics \& Plant Breeding, College of Agriculture, Chaudhary Charan Singh Haryana Agricultural University, Hisar, Haryana, India

*Corresponding author

\section{A B S T R A C T}

Keywords

F3 population, SSR markers,

Resistance, Stripe rust and Wheat

\section{Article Info}

Accepted: 04 October 2020 Available Online: 10 November 2020
To evaluate the presence of resistance genes parents (DBW17 and WH1105) and F3 population of cross DBW17 x WH1105 were screened for reaction to stripe rust using Modified Cobb's Scale and using SSR markers. Considering the inheritance pattern of resistance to yellow rust a ratio of 13:3 was observed for resistant to susceptible plants. For genotyping 99 primers were used out of which 15 primers were found to be polymorphic and were dispersed over the wheat genome (AABBDD), with allele range 2-5. A total of 32 alleles were detected in polymorphic markers. The average number of SSR alleles per locus was 2.13, with a range from 2 to 4 . PIC values of various SSR loci ranged from 0.44 to 0.66 . The hierarchical cluster analysis revealed that the F3 population along with their parents were mainly divided into two major clusters, I and II at a similarity coefficient of 0.54. Dendrogram confirmed that two parents were highly diversed and all of the progeny lines were interspersed between the two parents. These parents can be used for developing RIL's that could be used for QTL mapping to identify the resistance genes and chromosome location.

\section{Introduction}

Wheat (Triticum aestivum L.) has been defined as the 'King of cereals' because of the acreage, high productivity and the prominent position it holds in the international food grain trade. Wheat is a disomic allohexaploid $(2 \mathrm{n}=6 \mathrm{x}=42$, AABBDD) crop with seven pairs of chromosomes derived from three different genomes $\mathrm{A}, \mathrm{B}$ and $\mathrm{D}$ and has an extremely large genome size of $17 \times 10^{9}$ base pairs with more than $80 \%$ repetitive DNA.
During 2018-19, the area, production, productivity of India was 29.72 mha, 98.61 $\mathrm{mt}$ and $3.32 \mathrm{t} / \mathrm{ha}$, respectively (Anonymous, 2019).

Wheat production is constrained not merely due to limited natural resources and changing climate but to a great extent by emergence of new more virulent pathotypes of economically important pathogens. Multiple diseases can attack wheat crop but the fungal disease yellow rust caused by a biotroph 
pathogen Puccinia striiformis f. sp. tritici is one of the most devastating diseases and has become a major threat to breakdown of resistance because of appearance of new Pst races and is a major concern for breeders and farmers (Marsalis and Goldberg, 2006). The use of fungicides adds a significant extra cost to farmers and cause adverse effects to environment.

The most effective, environmentally sound and economic method to control the disease is growing resistant cultivars which require diverse, well-characterized and effective resistant genes.

In the past several decades, molecular techniques have provided useful tools for identification of resistance genes linked with molecular markers and these markers thus facilitate the successful selection in breeding process. More than 70 stripe rust resistance genes with official and provisional designations have been reported so far in wheat (McIntosh et al., 2010, Yang et al., 2016). Molecular markers viz., AFLP, RFLP, SSR and SNPs have been developed for genotyping many stripe rust resistance genes, such as Yr5, Yr10, Yr15, Yr26, Yr45, Yr53, Yr64 and Yr65 (Wang et al., 2008; Xu et al., 2013; Cheng et al., 2014; Yaniv et al., 2015, Alemu et al., 2019) and are useful tools for gene pyramiding to speed up the development of resistance in wheat cultivars. Closely linked SSR markers provide a powerful tool for pyramiding yellow rust resistance genes and marker assisted selection in breeding programmes due to its high polymorphism, repeatability, accuracy, repeatability, low cost, chromosome specificity and ease of handling (Gebrewahid et al., 2020; Jiang et al., 2013). The present study investigates the use of microsatellite markers to genotype the F3 population for yellow rust resistance genes.

\section{Materials and Methods}

\section{Plant Material}

The plant material comprised of two varieties viz., WH1105 and DBW17 and their F3 population lines. These were sown in 1 row of $2 \mathrm{~m}$ length. Infector rows were planted between the blocks and artificial inoculation using a mixture of races $46 \mathrm{~S} 102,47 \mathrm{~S} 103$ and $78 \mathrm{~S} 84$ of stripe rust pathogen was carried out under field conditions. Infected leaves containing uredospores were also directly rubbed with healthy leaves to spread the infection. The screening for reaction to stripe rust was done and on the basis of that, selected plants were classified as highly resistant (HR), moderately resistant (MR), moderately susceptible (MS) and highly susceptible (HS).

\section{Genomic DNA isolation}

CTAB (Cetyl Trimethyl Ammonium Bromide) extraction method given by Murray and Thompson (1980) modified by SaghaiMaroof et al., (1984) was used for genomic DNA isolation from the young leaves of wheat plants. Quantitative estimation of the isolated genomic DNA was done by using UV spectrophotometer at a wavelength of $260 \mathrm{~nm}$ as well as $280 \mathrm{~nm}$. Using the Beer-Lambert Law of 1.0 O.D. as $260 \mathrm{~nm}$ equivalent to 50 ng DNA per ml, the quantity of DNA was estimated by using the following formula:

DNA $(n g / \mu l)=$ O.D. A260 $\times$ Dilution factor $\times$ 50

Quality of DNA samples was checked by both UV spectrophotometer as well as by agarose gel electrophoresis.

\section{Molecular markers}

A total of 99 Simple sequence repeat (SSR) markers were used for studying molecular 
polymorphism in parental genotypes. All these primers were custom synthesized from Sigma Chemicals Co. USA.

\section{Polymerase Chain Reaction (PCR) Amplification}

PCR amplification reaction was carried out in applied biosystem thermocycler. The Optimization of PCR reaction was done by varying the concentrations of master mix ingredients. The optimized reaction contained 50ng DNA template in $10.00 \mu \mathrm{l}$ of master mix with $0.30 \mu \mathrm{l} \mathrm{MgCl} 250 \mathrm{mM}, 0.25 \mu \mathrm{l}$ dNTPs mix $(10 \mu \mathrm{M}), 0.20 \mu \mathrm{l}$ of Forward primer and Reverse primer each, $7.00 \mu$ Sterile distilled water and 3 units of Taq polymerase. The PCR conditions were set at $94^{\circ} \mathrm{C}, 4$ minutes for initial denaturation then again at $94^{\circ} \mathrm{C}, 1$ minute for further denaturation. Primer annealing temperature ranged from $46-73^{\circ} \mathrm{C}$ which existed for 1 minute and extension was attained at $72^{\circ} \mathrm{C}$ for 2 minutes then again $72^{\circ} \mathrm{C}, 10$ minutes for final primer extension. The cycle was repeated from step (ii) to (iv) for 35 times and the amplified products were stored at $-20^{\circ} \mathrm{C}$ till further use.

PCR amplified DNA fragments were resolved on $2.5 \%(\mathrm{w} / \mathrm{v})$ agarose gels. PCR amplified products were viewed under UV light using photo UV trans-illuminator and image was captured using gel documentation system.

\section{Allele Scoring}

Bands for SSR analysis were scored based on the presence (taken as 1) or absence (taken as 0 ) of bands. The size (in nucleotides base pairs) of the amplified bands was determined based on its migration relative to standard DNA marker (100 bp DNA ladder).

The binary data was used to calculate similarity genetic distance using 'simqual' sub-program of software NTSYS-PC (Rohlf,
1992) and dendrogram was constructed on similarity bases.

\section{Results and Discussion}

Plant breeders have to put continuous efforts to develop new varieties on fast track basis as the new virulent pathogens are arriving. The disease severity on leaves was evaluated by Modified Cobb's Scale in which rust severity was recorded as a percentage of leaf area infected. Some plants showed highly resistant reaction to yellow rust ( $0 \%$ infection) (Plate 1a), some showed resistant (5-10S) and moderately resistant (20S) (Plate 1b, 1c) while some showed moderately susceptible (40S), susceptible (60S) (Plate 1d) and highly susceptible reaction (100S) to yellow rust (Plate 1e). Taking into account the inheritance pattern, 78 plants were found resistant and 22 plants were susceptible to yellow rust (Table 1). A ratio of 13:3 was observed for resistant to susceptible plants which was confirmed by chi-square test $\left(\chi 2\right.$ cal. $=0.69, \chi^{2}$ tab. $=$ 3.841 ) and it was observed that the resistance was governed by two dominant genes with inhibitory epistasis. Singh et al., (2017) confirmed that resistance is governed by two genes by evaluating parental lines, F1, F2 populations as well as F3 and F4 families and F6, F7 RILs of bread wheat cross PBW621 x HD2967 for stripe rust. Chi-square analysis confirmed that resistant segregants possess two genes. Khanna et al., (2005) studied segregation for rust reaction in the F2, F3 and F5 generations of cross HD 2009 x WL711 for leaf rust and yellow rust that indicated that resistance to each of these rust diseases is based on two genes, each with additive effects.

DNA markers are used for genetic improvement through selection of desirable traits. Marker assisted selection (MAS) is expected to increase genetic response as they are least affected by environment thus 
increasing efficiency and accuracy of selection. Therefore, existing plant breeding techniques along with available molecular markers can help a breeder in developing superior wheat varieties resistant against major diseases in order to minimize yield losses. In present studies a total of 99 primers were used for genotyping of parents. Out of 99 primers, 15 were found to be polymorphic and remaining 84 gave monomorphic bands (Table 2). Ali et al., (2010) screened thirty five SSR primer pairs on the parents and on F2 population, the result indicated that most of resistant plants amplified same band as resistant parent while susceptible plants amplified same as susceptible parent as in the present study. Fifteen polymorphic SSR markers were dispersed over the wheat genome (AABBDD), with allele range 2-5. A total of 32 alleles were detected in polymorphic markers (Table 1) and the average number of SSR alleles per locus was 2.13, with a range from 2 (Xgwm95, Xgwm190, Xgwm268, Xgwm374, Xgwm408, Xgwm429, Xgwm437, Xgwm582, Xbarc76, Xbarc240, Xbarc353, Xwmc175, Xwmc215, Xwmc216) to 4 (Xgwm297). Sharma et al., (2010) used 25 SSR markers out of which ten microsatellite markers were found to be polymorphic and the average number of fragments were 5.6 per marker with number of amplified bands ranging from 1 to 15 . Similarly Rathi et al., (2018) used sixty microsatellite markers to characterize 49 wheat genotypes of which 23 showed polymorphism with a total of 170 alleles.

Table.1 Incidence of yellow rust disease on parents and F3 generation for its inheritance

\begin{tabular}{|c|c|c|c|c|c|c|c|}
\hline Parents/ & Screened & Resistant & Susceptible & $\begin{array}{c}\text { Resistant } \\
\text { tabulated } \\
\text { Susceptible } \\
\text { Ratio }\end{array}$ & $\begin{array}{c}\chi^{2} \\
\text { calculated }\end{array}$ & $\begin{array}{c}\chi^{2} \\
\text { Value }\end{array}$ & $\mathbf{p}$ \\
\hline DBW17 & 5 & 0 & 5 & & & & \\
\hline WH1105 & 5 & 5 & 0 & & & & \\
\hline F3 & 100 & 78 & 22 & $13: 3$ & 3.841 & 0.69 & 0.406 \\
\hline
\end{tabular}

Table.2 Allelic diversity in primers used to screen parents and F3 population

\begin{tabular}{|l|c|}
\hline Number of markers used & 99 \\
\hline Number of polymorphic markers & 15 \\
\hline Number of monomorphic markers & 84 \\
\hline Total number of alleles in polymorphic markers & 32 \\
\hline Average number of alleles & 2.13 \\
\hline
\end{tabular}




\section{Plate.1}

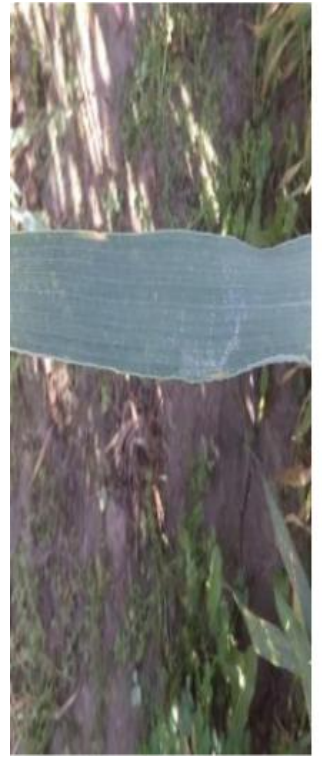

(a)

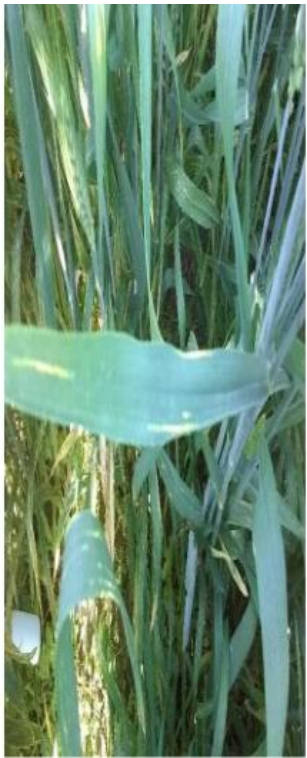

(b)

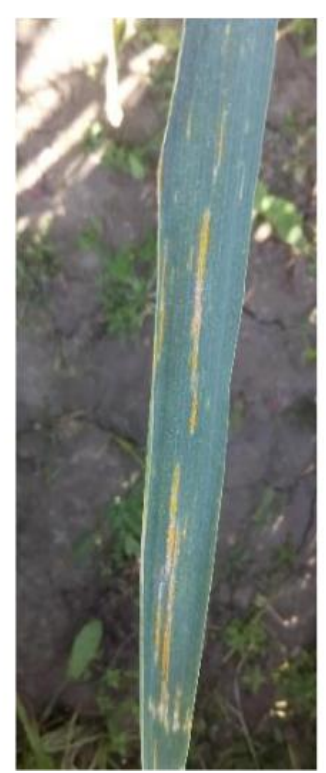

(c)

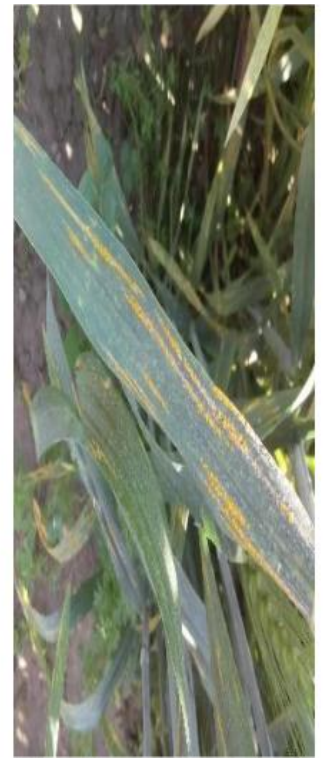

(d)

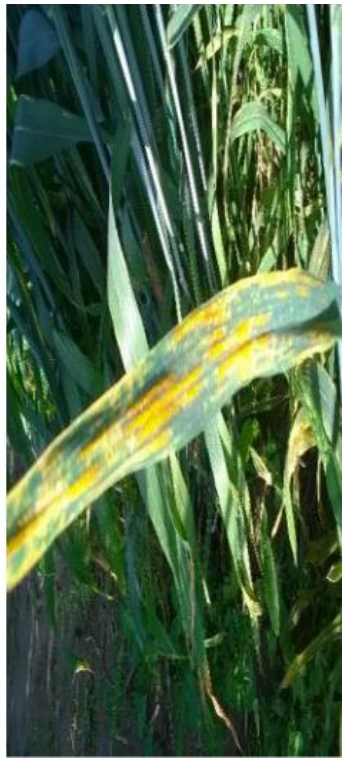

(e)

(a) Showing Traces of Yellow Rust (HR)

(b) Showing Resistant Reaction to Yellow Rust (R)

(c) Showing Moderately Resistant Reaction to Yellow Rust (MR)

(d) Showing Moderately Susceptible Reaction to Yellow Rust (MS)

(e) Showing Highly Susceptible Reaction to Yellow Rust (HS)

Plate.2 Polymorphism in F3 population using marker Xwmc175

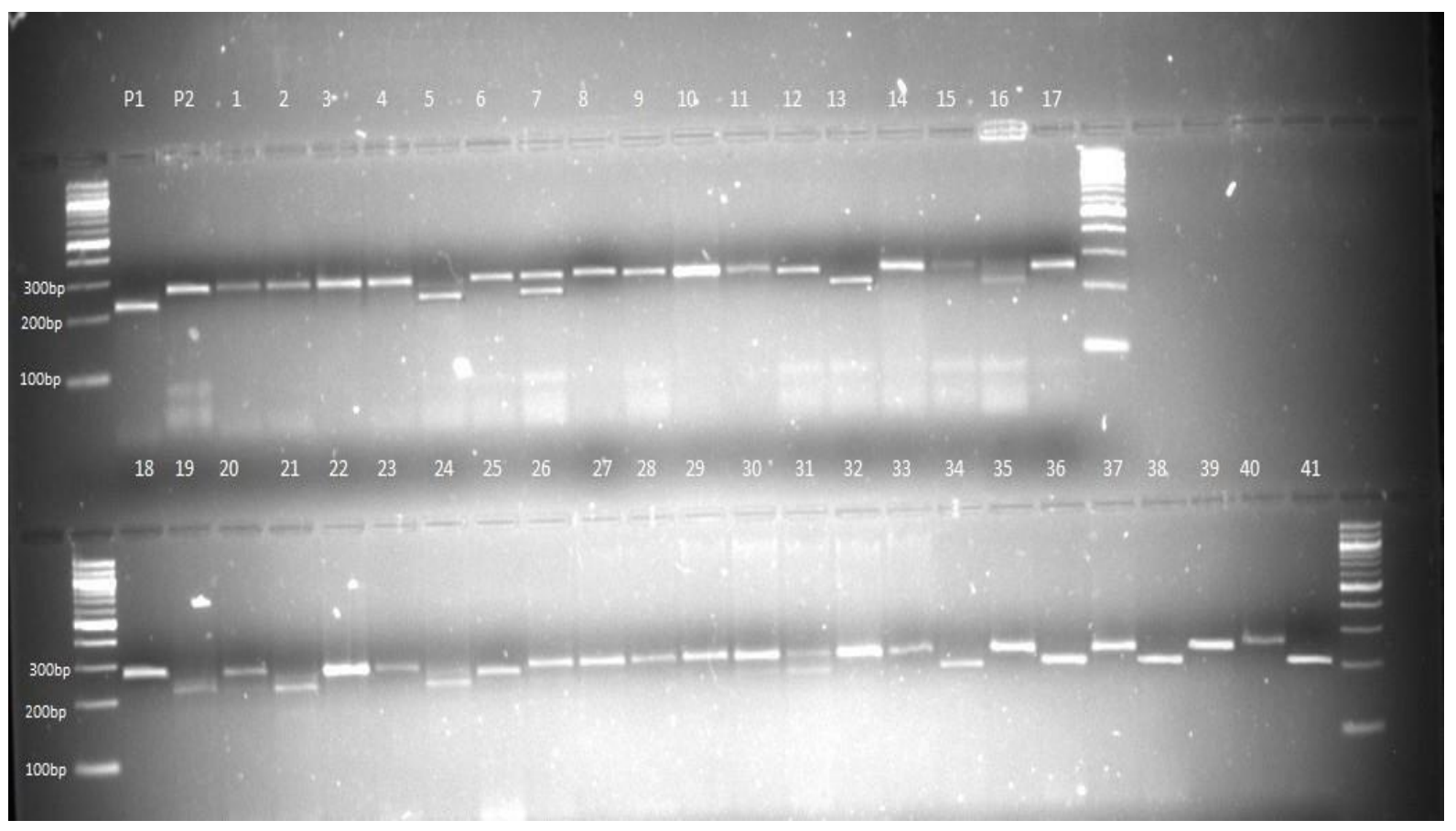


Table.3 Band size, allele number and PIC value of polymorphic markers in F3 population

\begin{tabular}{|l|l|c|c|c|c|}
\hline $\begin{array}{c}\text { S. } \\
\text { No. }\end{array}$ & SSR Primer & $\begin{array}{c}\text { Linkage } \\
\text { Group }\end{array}$ & $\begin{array}{c}\text { No. of } \\
\text { alleles }\end{array}$ & $\begin{array}{c}\text { Amplified } \\
\text { Fragment } \\
\text { size of } \\
\text { parents (bp) }\end{array}$ & $\begin{array}{c}\text { PIC } \\
\text { Value } \\
\text { (F3) }\end{array}$ \\
\hline $\mathbf{1}$ & Xgwm95 & & & & \\
\hline 2 & Xgwm190 (YrAC) & 2A & 2 & $130-180$ & 0.49 \\
\hline 3 & Xgwm268 (YrH52) & 5D & 2 & $190-260$ & 0.50 \\
\hline 4 & Xgwm297(YrMY37) & 7B & 2 & $150-180$ & 0.50 \\
\hline 5 & Xgwm374(YrCN19) & 2B & 2 & $150-190$ & 0.50 \\
\hline 6 & Xgwm408 & 5B & 2 & $150-210$ & 0.66 \\
\hline 7 & Xgwm429 (YrP81) & 2B & 2 & $250-300$ & 0.50 \\
\hline 8 & Xgwm437(Yr33) & 7D & 2 & $100-130$ & 0.61 \\
\hline 9 & Xgwm582(Yr9) & 7D & 2 & $120-200$ & 0.44 \\
\hline 10 & Xbarc76(Yr18) & 7A 1B,1D,5B & 2 & $200-240$ & 0.47 \\
\hline 11 & Xbarc240(YrSN104) & 2A & 2 & $200-230$ & 0.60 \\
\hline 12 & Xbarc353(Yr17) & 2B & 2 & $210-250$ & 0.50 \\
\hline 13 & Xwmc175(Yr5) & 5D & 2 & $200-240$ & 0.49 \\
\hline 14 & Xwmc215 & 1D & 2 & $100-160$ & 0.49 \\
\hline 15 & Xwmc216(YrCH42) & & 2 & 0.50 \\
\hline
\end{tabular}

Fig.1 Dendrogram showing the clustering pattern of F3 progenies of cross DBW17 x WH1105 using SSR marker

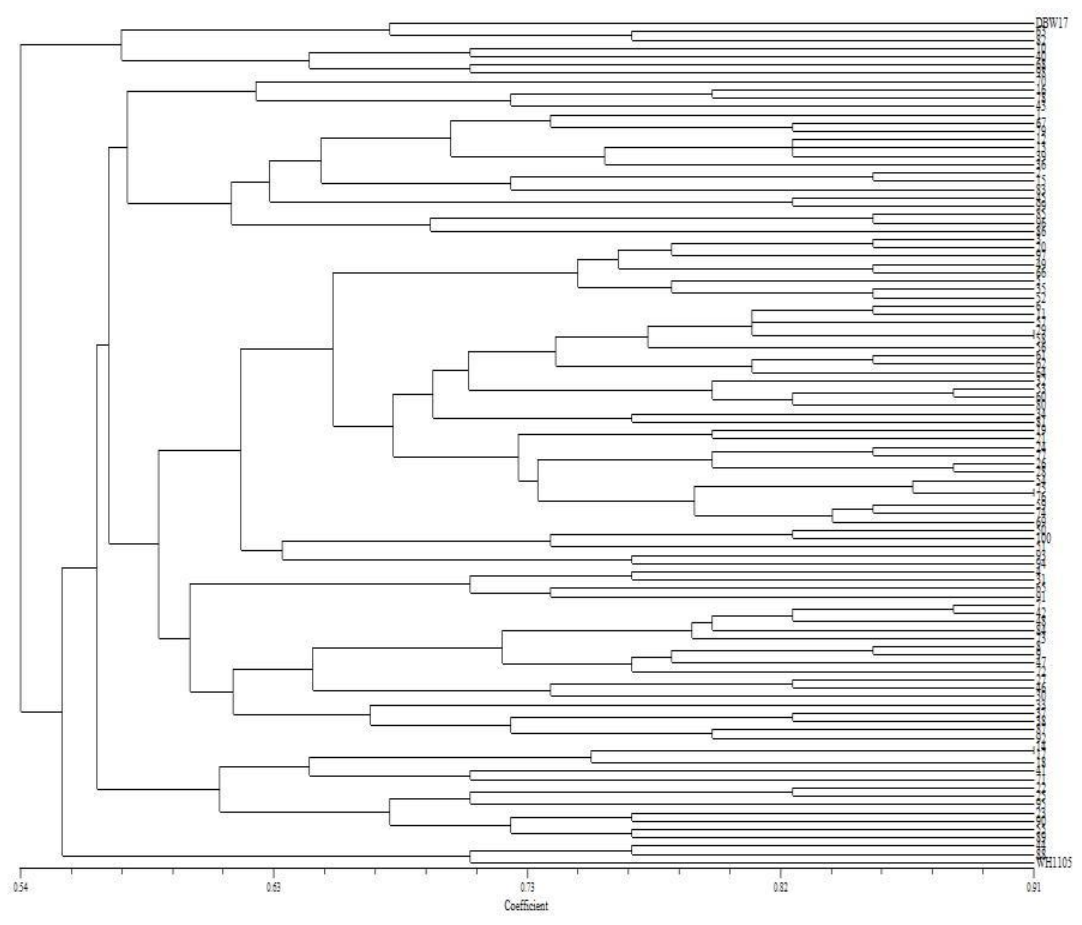


PIC (Polymorphic Information Content) is used to assess the potential of molecular markers. PIC values of various SSR loci ranged from 0.44 (Xgwm437) to 0.66 (Xgwm374) (Table 3). Tamimi et al., 2019 showed highest PIC value as 0.49 of SSR marker Xgwm162 in the analysis of genetic variability of wheat. Kara et al., 2020 assessed genetic variability of 17 bread wheat (Triticum aestivum L.) genotypes using 16 SSR markers. The Polymorphism Information Content (PIC) values per locus varied from 0.14 to 0.70 with an average of 0.48 and 0.49 . The high value of PIC is ascribed to the diverse nature of the wheat accessions and highly informative SSR markers. Xgwm374, Xgwm429 and Xbarc240 had PIC value more than 0.5 which can be considered highly useful for differentiation of wheat genotypes. Correspondingly, Gangwar et al., 2019 detected 79 alleles across the 21 loci. Six markers. were found highly informative as their PIC values were $>0.69$. These markers provided useful information on genetic divergence of newly emerged Pst pathotypes.

The photographs of electrophoretic gels showing SSR profiles of F3 population after amplification with different primers are presented in plate 2 .

\section{Cluster tree analysis in $\mathrm{F} 3$ population}

The bivariate data (1-0) of SSR primers were used to construct dendrogram using computer programme "Simqual NTSYS PC"- version 2.0. UPGMA was used to calculate the generated bivariate data matrix and genetic distances. The hierarchical cluster analysis revealed that the $\mathrm{F} 3$ population along with their parents were mainly divided into two major clusters, I and II at a similarity coefficient of 0.54 and these clusters were further subdivided into sub-clusters. The cluster I comprised of parental genotype DBW17 and cluster II comprised of parental genotype WH1105. It was confirmed by dendrogram that two parents were highly diversed and all of the progeny lines were interspersed between the two parents. The association among F3 generation with their parents is presented in the form of dendrogram in Fig. 1. Similarly the dendrogram generated by Meena et al., 2018 showed that F3 and F4 population derived from cross MAS25 (Aerobic rice) X IB370 (Lowland Basmati) were quite divergent and segregation among them were interspersed between the parents. Same findings were reported by Yashveer et al., 2020 where dendrograms were prepared for $\mathrm{BC} 1 \mathrm{~F} 3, \mathrm{BC} 2 \mathrm{~F} 2$ and F4 generations by UPGMA method. Each of the three generations was grouped into two clusters. Major cluster I consisted of Kharchia 65 while cluster II contained all plants of respective progeny with the parent genotype HD2967. These parents can be used for developing RIL's that could be used for QTL mapping to identify the genes for resistance and chromosome location.

From the present studies it could be concluded that for the identification and utilization of potential genotypes, evaluation of germplasm is an important step in plant breeding. The development of molecular marker technologies during the last twenty years has revolutionized the genetic analysis of crop plants. In this population SSR markers linked to genes for the trait of interest were used to identify and select individuals who possess yellow rust resistant genes, thus improving the efficiency of traditional plant breeding by facilitating indirect selection and fastening the process of variety development program, specifically in gene pyramiding which is otherwise very difficult to do.

\section{Acknowledgements}

Authors are thankful to the Head of the Department, Department of Genetics and Plant Breeding, Dean, College of Agriculture, Hisar, CCSHAU and Dr. Mukesh Saini (Assistant Professor) for providing facilities to carry out the present study which is highly appreciated. 


\section{References}

Alemu S.K., Badebo A., Tesfaye K., Uauy C., 2019. Identification of Stripe Rust Resistance in Ethiopian Durum Wheat by Phenotypic Screening and Competitive Allele Specific PCR (KASP) SNP Markers. Plant Pathology and Microbiology 10: 483.

Ali, M., Ji W.Q., Hu Y.G., Baloch G.M., Zhong H., Wang C.Y., 2010. Molecular implications from SSR markers for Stripe rust (Puccinia striiformis f.sp. tritici) resistance gene in bread wheat line N95175. Pakistan Journal of Botany, 42(1): 383-390.

Al-Tamimi, A.J. and Al-Janabi, A.S., 2019. Genetic diversity among bread wheat genotypes using RAPD and SSR markers. SABRAO Journal of Breeding and Genetics, 51(3): 325-339.

Anonymous , 2019. Progress report of All India Coordinated Wheat and Barley Improvement Project 2018-19. 01, Crop Improvement. Directorate of Wheat Research, Karnal, India.

Cheng, P. , Xu, L.S., Wang, M.N., See, D.R., Chen, X.M., 2014. Molecular mapping of genes Yr64 and Yr65 for stripe rust resistance in hexaploid derivatives of durum wheat accessions PI 331260 and PI 480016. Theoretical and Applied Genetics, 127(10): 2267-2277.

Gangwar, O.P., Kumar, S., Kashyap, P.L., Bhardwaj, S.C., Prasad, P., Savadi, S. and Khan, H., 2019. Virulence and molecular analysis of atypical pathotypes of yellow rust pathogen in India. Indian Phytopathology, 72(2): 187-194.

Gebrewahid, T.W., Zhang, P., Zhou, Y., Yan, X., Xia, X., He, Z., Liu, D. and Li, Z. 2020. QTL mapping of adult plant resistance to stripe rust and leaf rust in a Fuyu 3/Zhengzhou 5389 wheat population. The Crop Journal, 8(4): 655-665.

Jiang, G.L., 2013. Molecular markers and markerassisted breeding in plants. Plant breeding from laboratories to fields, 45-83.

Kara, K., Rached-Kanouni, M., Mnasri, S., Khammar, H. and M'barek, B.N., 2020. Genetic variability assessment in bread wheat (Triticum aestivum) grown in Algeria using microsatellites SSR markers.
Biodiversitas Journal of Biological Diversity, 21(6).

Khanna, R., Bansal, U.K. and Saini, R.G., 2005. Genetics of durable resistance to leaf rust and stripe rust of an Indian wheat cultivar HD2009. Journal of Applied Genetics, 46(3): 259-263.

Marsalis, M.A., and Goldberg, N.P., 2006. Leaf, stem and stripe rust diseases of wheat. New Mexico State University Guide A-415.

Mclntosh, R., Dubcovsky, J., Rogers, J., Morris, C., Appels, R. and Xia, X., 2010. Catalogue of gene symbols for wheat: 2010 supplement. Annual Wheat Newsletter, 56: 273-282.

Meena, R.K., Kumar, K., Rani, K., Pippal, A., Bhusal, N., Jain, S. and Jain, R.K., 2018. Genotypic screening of water efficient extra-long slender rice derived from MAS25 X IB370. Journal of Rice Research, 6(194): 2.

Murray, M.G. and Thompson, W.F., 1980. Rapid isolation of high molecular weight plant DNA. Nucleic Acid Resources, 8: 43214325.

Rathi, M., Kumar, M., Kumar, V., Pooja and Chaudhary, L., 2018. Use of microsatellite markers for assessing genetic variability in wheat genotypes for yellow rust resistance. International Journal of Current Microbiology and Applied Sciences, 7(12): 1907-1914.

Rohlf, F.J., 1992. NTSYS-pc: numerical taxonomy and multivariate analysis system. Applied Biostatistics.

Saghai-Maroof, M.A., Soliman, K.M., Jorgensen, R.A. and Allard, R.W., 1984. Ribosomal DNA spacer-length polymorphism in Barley: Mendelian inheritance, Chromosomal-location and population dynamics. Proceedings of National Academy and Sciences, U.S.A. 81: 80148019.

Sharma, J., Goyal, N., Singh, A., Pallavi, J.K., Sonah, H. and Gupta, P., 2010. Assessment of genetic relationships among bread wheat (Triticum aestivum $\mathrm{L}$ em. Thell) genotypes using microsatellite markers. International Journal of Applied Agricultural Research, 5(5): 575-582.

Wang, C.M., Zhang, Y.P., Han, D.J., Kang, Z.S., 
Li, G.P., Cao, A.H. and Chen, P.D., 2008. SSR and STS markers for wheat stripe rust resistance gene Yr26. Euphytica, 159(3): 359-366.

Xu, L.S., Wang, M.N., Cheng, P., Kang, Z.S., Hulbert, S. and Chen, X.M., 2013. Molecular mapping of $\mathrm{Yr} 53$, a new gene for stripe rust resistance in durum wheat accession PI480148 and its transfer to common wheat. Theoretical and Applied Genetics, 126(2): 523-533.

Yang, E., Li, G., Li, L., Zhang, Z., Yang, W., Peng, Y., Zhu, Y., Yang, Z. and Rosewarne, G.M., 2016. Characterization of stripe rust resistance genes in the wheat cultivar
Chuanmai 45. International journal of molecular sciences, 17(4): 601.

Yaniv, E., Raats, D., Ronin, Y., Korol, A.B., Grama, A., Briana, H., Dubcovsky, J., Schulman, A.H. and Fahima, T., 2015. Evaluation of marker-assisted selection for stripe rust resistance gene $\mathrm{Yr} 15$, introgressed from wild emmer wheat. Molecular Breeding, 35(1): 35-43.

Yashveer, S., Singh, V. and Kumar, P., 2020. Morphological analysis and screening of wheat generations derived from HD2967x Kharchia65 for salt tolerance. Journal of Environmental Biology, 41(4): 695-702.

\section{How to cite this article:}

Vijeta Gupt, Mukesh Kumar, Vikram Singh and Lakshmi Chaudhary. 2020. SSR Markers based Molecular Assessment of Stripe Rust Resistance Genes in F3 Population of Cross DBW17 x WH1105 of Wheat (Triticum aestivum L.). Int.J.Curr.Microbiol.App.Sci. 9(11): 176-184. doi: https://doi.org/10.20546/ijcmas.2020.911.021 